\title{
Maximum Longevities of Rhizophora apiculata and R. mucronata Propagules ${ }^{1}$
}

\author{
fudy Z. Drexler ${ }^{2}$
}

\begin{abstract}
The longevity of viviparous mangrove seedlings (propagules) in seawater is a key factor determining their ability to survive dispersal both locally and across large expanses of ocean. The purpose of this experiment was to determine the maximum longevities of propagules from two common Pacific mangrove species: Rbizophora mucronata Lamk. and Rbizophora apiculata Bl. Propagules from each of these species were placed in outdoor tubs with continuously flowing seawater. The condition of each propagule was monitored until it sank or started to rot. Propagules were then planted to determine viability. After planting, $50 \%$ of $R$. apiculata propagules and $21 \%$ of $R$. mucronata propagules were viable. For both species, mortality of propagules was strongly related to the length of the floating interval. Maximum longevities for $R$. $m u$ cronata and $R$. apiculata propagules were 150 (median $=70$ ) and 89 days (median $=7$ ), respectively. Rhizophora mucronata propagules appeared to be better equipped for long-distance dispersal, yet had low survivorship that would decrease overall dispersal opportunities. In comparison, $R$. apiculata propagules had higher survivorship yet shorter longevity and, thus, appeared to be better equipped for shorter distance dispersal.
\end{abstract}

Several species of mangroves produce viviparous seedlings (propagules) that are buoyant and can disperse in seawater. The limits for such dispersal have long been the topic of speculation, especially among those seeking to explain the presence of closely related species in distant areas or the total absence of mangroves from suitable habitats (Guppy 1906, Ridley 1930, Tomlinson 1986, Duke 1992).

One of the chief factors controlling the dispersal of viviparous mangroves is longev-

${ }^{1}$ This is contribution no. 1102 of the Hawai'i Institute of Marine Biology. Manuscript accepted 27 April 2000.

2 USDA Forest Service, Institute of Pacific Islands Forestry, 1151 Punchbowl St., rm. 323, Honolulu, Hawai'i 96813. Current address: U.S. Geological Survey, California State University, Placer Hall, 6000 J St., Sacramento, California 95819-6129 (E-mail: jdrexler@usgs.gov).

Pacific Science (2001), vol. 55, no. 1:17-22 ity, the number of days propagules remain buoyant and viable in seawater. Longevity of mangrove propagules varies between different species. Rhizophora mangle propagules can remain viable in laboratory vessels for over 12 months (Davis 1940) and can float throughout a 3-month period (Ellison 1996). Rbizophora harrisonii (now referred to as $R$. racemosa [pers. comm., N. Duke, Department of Botany, University of Queensland, St. Lucia, Australia]) and Pelliciera rbizophorae propagules are capable of regaining buoyancy after an initial sinking stage and can survive 3 months floating in seawater with no mortality (Rabinowitz 1978). Avicennia marina propagules may remain viable, either exposed by tides or totally submerged (in enclosures in the field), for up to 5 months during enforced dispersal (Clarke 1993). None of these studies, however, sought to determine the maximum longevities of propagules, which are essential for assessing long-distance dispersal capability.

The aim of this experiment was to determine maximum longevities of propagules from two common Pacific mangrove species, Rbizophora mucronata Lamk. and Rbizophora apiculata $\mathrm{Bl}$. Longevities of both species were 
then used to compare their long-distance dispersal capabilities.

\section{MATERIALS AND METHODS}

The island of Kosrae, Federated States of Micronesia $\left(5^{\circ} \mathrm{N}, 163^{\circ} \mathrm{E}\right)$ was chosen for propagule collection because of the large, productive, and intact stands of both species that grow interspersed in mangrove forests in that location (Ewel et al. 1998). On 6-7 October 1997, mature $R$. apiculata and $R$. mucronata propagules were collected from trees within riverine populations on the northern and western parts of the island. Kosrae is a high volcanic island approximately $112 \mathrm{~km}^{2}$ in size that contains 1562 ha of mangroves represented by seven species (Whitesell et al. 1986). The watersheds sampled are relatively pristine, with only minimal impact from agricultural activities and logging. Average air temperature on Kosrae is approximately $27.4^{\circ} \mathrm{C}$ (Mueller-Dombois and Fosberg 1998), seawater temperature is approximately $28-30^{\circ} \mathrm{C}$, and salinity outside the fringing reef is between 33.6 and 34.5 ppt (unpubl. data).

After collection, propagules damaged from boring insects were discarded, so that maximum propagule longevities could be determined without confounding effects from herbivory. In total, $82 R$. apiculata and $104 R$. mucronata propagules were wrapped in moist newspaper, sealed in plastic bags, placed in sturdy cardboard boxes, and shipped overnight to Honolulu, Hawai'i, by air (this method has been used frequently for transporting mangrove propagules [pers. comm., Edward Proffitt, U.S. Geological Survey, National Wetlands Research Center, Lafayette, Louisiana]). On 8 October, each propagule was weighed, measured, and labeled. On the following day propagules were taken to the Hawail $i$ Institute of Marine Biology (HIMB), Coconut Island, situated in Kāne'ohe Bay on O'ahu, Hawai'i $\left(21^{\circ} \mathrm{N}\right.$, $157^{\circ} \mathrm{W}$ ). At HIMB, R. mucronata and $R$. apiculata propagules were evenly distributed into four 189.2-liter and four 60.6-liter plastic tubs, respectively, on two outdoor platforms. Temperature and salinity of seawater pumped into the tubs ranged from 23 to $27^{\circ} \mathrm{C}$ and from 35 to $36 \mathrm{ppt}$, respectively. To simulate open-ocean conditions, small holes were drilled in the sides of the tubs to facilitate circulation of water. Tubs were cleaned every week to keep the propagules and plumbing system as free as possible from algae. This was done to protect the propagules from excessive amounts of algal growth that could have altered decay rates and buoyancy. Excessive algal growth was largely an artifact of the high surface area of the tubs combined with the nutrient regime of Kāne'ohe Bay and, therefore, not typical of open-ocean conditions.

The condition of the propagules was checked twice per week for the first 2 weeks and once per week thereafter. Propagules were removed from the experiment when they had sunk to the bottom of tubs or when their epicotyl and a substantial portion of the hypocotyl was blackened or contained rot. Sinking was used as an indicator for terminating the flotation trial because the chance of propagules regaining buoyancy (a behavior demonstrated by Rabinowitz [1978] in aquariums for $R$. racemosa and Pelliciera rbizophorae) was deemed slim for a pool of propagules dispersing over the open ocean. Each time propagules were checked, propagules that had sunk were immediately taken to the Maunawili Agricultural Research Station (MARS), Maunawili, O'ahu, to establish viability. Six $R$. mucronata propagules were removed from the experiment after sinking because of severe rot. At MARS each propagule was planted in a separate container in soil made up of equal parts peat moss and Sunshine $4 \mathrm{mix}$ aggregate plus (perlite/soil mixture). Soil was kept moist by watering twice daily with fresh water. Fresh water was used for logistic reasons, yet this choice should not have affected growth of these particular species because propagules were collected from riverine locations that are routinely exposed to a predominance of fresh water, and research has demonstrated that $R$. apiculata, $R$. mucronata, and several other mangrove species are able to grow quite well in fresh water for many years (Davis 1940, Vu van Cuong 1964, Teas 1979). Propagules 
were determined to be viable only when root systems became established and initial leaves sprouted from the epicotyl. Such a definition of viability does not imply successful establishment, only that establishment is at least possible.

Logistic regression analysis was carried out to determine the relationship between flotation interval and mortality of propagules. Data were analyzed using Statistical Analysis System software (release 6.12) (SAS Institute 1996).

\section{RESULTS}

Rhizophora mucronata propagules collected for the experiment had a mean length of $57.1 \mathrm{~cm}$ $(\mathrm{SD}=8.22)$ and a mean weight of $107.5 \mathrm{~g}$ $(\mathrm{SD}=24.05)$. Rbizophora apiculata propagules were much smaller, averaging $29.0 \mathrm{~cm}$ in length $(\mathrm{SD}=4.08)$ and $19.9 \mathrm{~g}(\mathrm{SD}=4.44)$. These size ranges fit within the size classification $\left(<1000 \mathrm{~cm}^{3}\right)$ attributed to these species by Duke et al. (1998).

Upon planting, the viability of propagules differed greatly between species. For $R$. apiculata, 41 propagules were found viable and 41 nonviable after planting. For $R$. mucronata, 21 propagules were found viable, and 77 were nonviable. For both species, results of logistic regression revealed a strong relationship between the duration of the floating interval and mortality of propagules (Table 1). The fact that propagules had low mortality after floating for short periods of time strongly suggests that watering with fresh water after planting did not negatively impact propagule viability.
The longevity of viable propagules (length of floating interval) averaged 15 days for $R$. apiculata (SD $=25$, median $=7$ ) and 53 days for $R$. mucronata $(\mathrm{SD}=45$, median $=70)$. The maximum longevity for propagules was 89 days for $R$. apiculata and 150 days for $R$. mucronata (Figure 1).

\section{DISCUSSION}

Maximum longevities for $R$. apiculata and $R$. mucronata propagules are similar to the upper limits of longevities found in experiments using other mangrove species. The 150-day limit for $R$. mucronata compares very closely to the 5-month maximum found during forced dispersal for $A$. marina propagules (Clarke 1993). The 89-day limit for R. apiculata is just short of the $>3$-month period for $R$. racemosa and Pelliciera rbizophorae (Rabinowitz 1978) and the $>3$-month period for $R$. mangle (Ellison 1996). Because propagules used in this experiment were free from effects of herbivory and desiccation and came from trees growing under highly favorable conditions (e.g., high rainfall, no seasonality, high average temperature, strong sunlight, and lack of major disturbance [Alongi 1998, Ewel et al. 1998]), these results represent a fair estimate of maximum longevities for $R$. $m u$ cronata and $R$. apiculata within their larger populations. However, these longevity estimates probably represent lower limits of possible maximums within the larger population of each species given that maximum longevities are highly dependent on sample size, sample sizes were relatively small in this

TABLE 1

Logistic Regression Models for Relationships between Proportion of Nonviable Propagules (Dependent Variable) and Duration of Floating Interval (DFI)

\begin{tabular}{llccc}
\hline \hline Data set & Variable & DF & Wald Chi Square & $\begin{array}{c}P>\text { Chi } \\
\text { Square }\end{array}$ \\
\hline All propagules $^{*}$ & DFI & 1 & 42.11 & 0.0001 \\
R. apiculata & DFI & 1 & 12.28 & 0.0005 \\
R. mucronata & Intercept & 1 & 11.95 & 0.0005 \\
& DFI & 1 & 25.29 & 0.0001 \\
\hline
\end{tabular}

${ }^{*}$ Intercept term was not significant at $P<0.05$. 


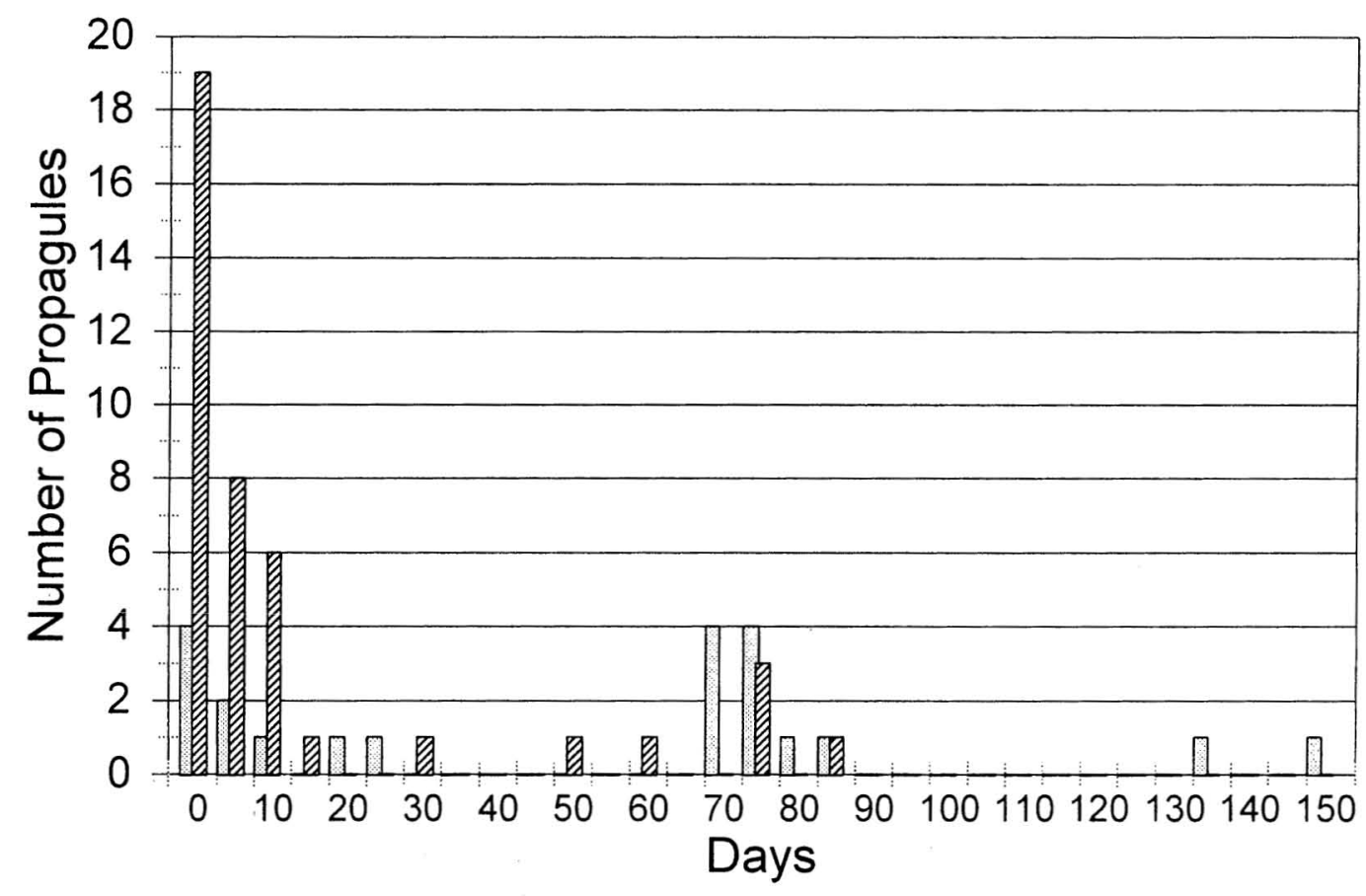

R. mucronata

R. apiculata

FIGURE 1. Longevity (floating interval for viable propagules) of $R$. apiculata and $R$. mucronata propagules.

study, and the distribution of longevities for both species was quite skewed (Figure 1).

To calculate the potential distances that $R$. mucronata and $R$. apiculata could travel in 150 and 89 days, respectively, physical measurements concerning the behavior of propagules in waves and ocean currents are required (pers. comm., P. Niiler, Scripps Institution of Oceanography, University of California, San Diego). Such information, however, is currently lacking. Furthermore, any such calculations are highly dependent on localized wind speed and ocean currents and, therefore, would have to be made for a particular trajectory. Nevertheless, a study conducted on the dispersal of athletic shoes spilled in the North Pacific can serve as an example of how far and at what rate partially submerged objects such as propagules can travel. Ebbesmeyer and Ingraham (1992) reported that within 174-211 days of the spill, a small subset of these shoes washed up on beaches in Washington and Vancouver Island (a distance of approximately $2800 \mathrm{~km}$ covered at roughly $15 \mathrm{~km} /$ day).

Although it is not currently possible to translate longevities into actual dispersal distances, the differences in longevities between the two species still suggest important differences in their relative dispersal capabilities. Even though only 2\% of the $104 R$. mucronata propagules had longevities between 130 and 150 days, in a much larger population (as explained above) several more individuals are likely to have longevities in that range and possibly greater. Propagules with such longevities would be capable of dispersing for long periods, and thus long distances in the ocean. For $R$. apiculata $5 \%$ of propagules had longevities $\geq 77$ days, indicating that this 
species may also be capable of dispersing for an extended period, but much shorter than $R$. mucronata. Median values for longevities (70 and 7 days, for $R$. mucronata and $R$. apiculata, respectively) also suggest that $R$. mucronata would be a better disperser because this species, unlike $R$. apiculata, did not have a sharp drop-off in longevity with time (Figure 1). However, another important aspect to consider is the relative amount of propagules produced by both species. The limited literature on reproductive material indicates that $R$. mucronata produces approximately 0.12 tons/ ha/yr of reproductive material (Amarasinghe and Balasubramaniam 1992), whereas $R$. apiculata produces approximately 2.6 tons $/ \mathrm{ha} / \mathrm{yr}$ of reproductive material (Bunt 1982). Although these two studies are by no mean an adequate survey of the subject, they suggest that $R$. apiculata might be a stronger disperser than $R$. mucronata in practical terms (i.e., absolute numbers of propagules dispersed).

The extended capability of propagules to remain buoyant and viable is not an acknowledgment of actual dispersal ability. For propagules to disperse successfully over large distances, longevity, wind, ocean currents, lack of herbivory, and establishment must all work together. The small amount of information on actual dispersal capabilities shows that most mangrove propagules do not disperse more than $1 \mathrm{~km}$ from their point of origin (Clarke 1993), and, in certain instances, as little as $65 \mathrm{~m}$ (Chan and Husin 1985) or even $3 \mathrm{~m}$ (McGuinness 1997). However, Davis (1940) found that Rhizophora mangle propagules carried by ocean currents could disperse at least $100 \mathrm{~km}$. Clearly, more information on maximum dispersal capabilities for viviparous mangrove species is needed along with additional information on propagule longevities. Such work together with genetic analyses of particular populations (e.g., Sun et al. 1998) could be quite useful in addressing questions related to mangrove biogeography.

\section{ACKNOWLEDGMENTS}

I thank E. Waguk and J. Lynch for their help in collecting propagules and E. Cox, P. Jokiel,
J. Allen, K. Krauss, V. Yap, and K. Ewel for their help in carrying out the experiment. Thanks also go to J. Baldwin for statistical advice and J. Allen, N. Duke, K. Ewel, and the anonymous reviewers for their insightful reviews of the manuscript.

\section{Literature Cited}

Alongi, D. M. 1998. Coastal ecosystem processes. CRC Press, Boca Raton, Florida.

Amarasinghe, M. D., and S. Balasubramaniam. 1992. Net primary productivity of two mangrove forest stands on the northwestern coast of Sri Lanka. Hydrobiologia 247:37-47.

Bunt, J. S. 1982. Studies of mangrove litter fall in tropical Australia. Pages 223-238 in B. F. Clough, ed. Mangrove ecosystems in Australia: Structure, function and management. Australian National University Press, Canberra.

Chan, H. T., and N. Husin. 1985. Propagule dispersal, establishment, and survival of Rbizophora mucronata. Malays. For. 48 (4): 324-329.

Clarke, P. J. 1993. Dispersal of grey mangrove (Avicennia marina) propagules in southeastern Australia. Aquat. Bot. 45: 195-204.

Davis, J. H., Jr. 1940. The ecology and geologic role of mangroves in Florida. Pap. Tortugas Lab. 32:307-412.

Duke, N. C. 1992. Mangrove floristics and biogeography. Pages 63-100 in A. I. Robertson and D. M. Alongi, eds. Tropical mangrove ecosystems, coastal and estuarine studies. American Geophysical Union, Washington, D.C.

Duke, N. C., M. C. Ball, and J. C. Ellison. 1998. Factors influencing biodiversity and distributional gradients in mangroves. Global Ecol. Biogeogr. Lett. 7:27-47.

Ebbesmeyer, C. C., and W. J. Ingraham Jr. 1992. Shoe spill in the North Pacific. Eos 73 (34): 361, 365.

Ellison, J. C. 1996. Pollen evidence of Late Holocene mangrove development in Bermuda. Global Ecol. Biogeogr. Lett. 5:315326.

Ewel, K. C., J. A. Bourgeois, T. G. Cole, and 
S. Zheng. 1998. Variation in environmental characteristics and vegetation in high-rainfall mangrove forests, Kosrae, Micronesia. Global Ecol. Biogeogr. Lett. 7:49-56.

Guppy, H. B. 1906. Observations of a naturalist in the Pacific between 1896 and 1899. Vol. 2. Plant-dispersal. Macmillan, New York.

McGuinness, K. A. 1997. Dispersal, establishment and survival of Ceriops tagal propagules in a north Australian mangrove forest. Oecologia (Berl.) 109:80-87.

Mueller-Dombois, D., and F. R. Fosberg. 1998. Vegetation of the tropical Pacific Islands. Springer-Verlag, New York.

Rabinowitz, D. 1978. Dispersal properties of mangrove propagules. Biotropica 10 (1): 47-57.

Ridley, H. N. 1930. The dispersal of plants throughout the world. L. Reeve and Co., Ltd., Ashford, Kent, United Kingdom.

SAS Institute. 1996. SAS/CPE software ref- erence, Version 6, 2nd ed. SAS Institute, Cary, North Carolina.

Sun, M., K. C. Wong, and J. S. Y. Lee. 1998. Reproductive biology and population genetic structure of Kandelia candel (Rhizophoraceae), a viviparous mangrove species. Am. J. Bot. 85 (11): 1631-1637.

Teas, H. J. 1979. Silviculture with saline water. Pages 117-161 in A. Holaender, ed. Biosaline concept. Plenum, New York.

Tomlinson, P. B. 1986. The botany of mangroves. Cambridge University Press, Cambridge, United Kingdom.

Vu van Cuong, H. 1964. Flore et vegetation de la mangrove de la region de Saigon-Cap Saint Jaques, Sur Viet-Nam. Ph.D. thesis, University of Paris, France.

Whitesell, C. D., C. D. Maclean, M. C. Falanruw, T. Cole, and A. Ambacher. 1986. Vegetation survey of Kosrae, Federated States of Micronesia. U.S. For. Serv. PSW-17. 